$\mathcal{O}_{\text {http://dx.doi.org/10.3765/sp.4.5 }}^{\text {Semantics \& Pragmatics Volume 4, Article 5: 1-44, } 2011}$

\title{
Wh-islands in degree questions: A semantic approach
}

\author{
Márta Abrusán \\ University of Oxford
}

Received 2010-08-12 / Decision 2010-10-17 / Revision Received 2011-04-08 / Decision 2011-05-21 / Revision Received 2011-08-06 / Published 2011-09-o9

\begin{abstract}
It is proposed that wh-islands with degree questions are unacceptable because they cannot be given a most informative true answer. Wh-islands thus are shown to be similar to other cases of weak islands which have been argued to result from Maximization Failure, in particular negative islands (cf. Fox \& Hackl 2007).
\end{abstract}

Keywords: questions, weak islands, degree semantics, question-embedding verbs

\section{Introduction}

This paper argues that the oddness of wh-islands, illustrated below in (1b), is a semantic rather than a syntactic phenomenon.

(1) a. Which glass of wine do you know whether you should poison $t$ ?

b. *How much wine do you know whether you should poison $t$ ?

The traditional, syntactic explanation of the contrast between (1a) and (1b) runs as follows. Both questions in (1) violate a syntactic constraint of locality that prohibits long movement. However (1a) is still acceptable, in contrast with (1b), because the wh-phrase being 'referential' it can establish a link with its trace position via a mechanism that is not subject to locality: binding (cf. Rizzi 1990).

Yet, it has been notoriously difficult to pin down the exact notion of 'referentiality' that makes some but not other extractees bindable. It has also been long observed (most importantly in Kroch 1989) that even classic cases of wh-islands can be significantly ameliorated by certain contexts. Further, it seems that there is a difference among interrogative verbs with respect

(C)2011 Márta Abrusán

This is an open-access article distributed under the terms of a Creative Commons NonCommercial License (creativecommons.org/licenses/by-nc/3.o). 
to the strength of the island effect they induce. Finally, it seems that some modals can improve the acceptability of wh-islands, at least in certain, highly specific contexts. These cases pattern together with other examples of weak islands that have been shown recently to be sensitive to similar effects of modal obviation: negative islands (Fox \& Hackl 2007) and presuppositional islands (Abrusán 2011).

Fox \& Hackl (2007) have argued that the unacceptability of negative degree islands such as "How fast didn't Bill drive? follows from the fact that they cannot receive a maximally informative true answer. This paper proposes that this idea can also explain the oddity of $w h$-islands in degree questions: these islands also arise because it is not possible to find a maximally informative true answer to them. Contextual effects are observed because sometimes a maximally informative answer can only be found in certain highly specific contexts which are rather unintuitive. Once such a context is supplied, the questions improve. Modal obviation effects in turn follow as a logical property, as was shown in Fox 2007.

The paper is organized as follows: After discussing briefly the relevant background to this paper in Section 2, Section 3 presents the core of the proposal. Section 4 discusses the case of context sensitivity of islands as well as the cases of modal obviation. Section 5 concludes the paper.

\section{Background}

\subsection{Syntactic proposals}

The traditional approach to the problem of $w h$-islands has been syntactic. Interestingly, the most successful syntactic approaches crucially rely on an ill-defined notion of 'referentiality.' This, as has been noted since Szabolcsi \& Zwarts 1990, not only raises the question whether these approaches can be maintained, but also suggests that a semantic approach could be more appropriate.

According to the influential theory of Relativised Minimality (cf. Rizzi 1990, Cinque 1990 and subsequent work), only local movement chains are allowed by the rules of syntax. Local chains, roughly speaking, are those that do not cross any clausal or nominal phrasal boundaries. Given this theory of locality, (2a) is allowed by grammar because the movement chain is composed of only local links $<$ which glass of wine, $t^{\prime}, t>t^{\prime}$ occupying a position in the specifier of the embedded CP. But in (2b) the intermediate position is filled by 
Wh-islands in degree questions

whether and therefore only long movement is possible. Because of this, only a non-local chain $<$ how much wine, $t>$ could be established. This, however, counts as a violation of locality and is disallowed.

(2) a. Which glass of wine do you think $t^{\prime}$ that you should poison $t$ ?

b. "How much wine do you know whether you should poison $t$ ? (=1b)

The locality violation exemplified above can be circumvented in certain cases, as shown below:

(3) Which glass of wine do you know whether you should poison $t_{1}$ ? (=1a)

In this case the specifier position of the embedded $\mathrm{CP}$ is still filled by whether, yet movement appears to be possible. According to various authors, the reason behind the difference between (2b) and (3) resides in some special property that the phrase which glass of wine possesses, but not how much wine. This property has been argued to be the property of being $\theta$-marked (Chomsky 1986), referential or D-linked (Pesetsky 1987, Rizzi 1990) or specific (Starke 2001). The most influential of these, Rizzi (1990) proposes that the reason why the extra property of being referential helps is that referential phrases can receive a referential index, which in turn enables the trace to be semantically bound, where semantic binding is assumed not to be subject to the locality conditions of movement. Thus in (2b) no link can be established between the moved element and the trace but in (3) such a link can be created by binding and so (3) is acceptable.

Cinque (1990) argues that a similar explanation is available for why amount $w h$-questions fail to be ambiguous in $w h$-island contexts. Cf. the example below:

(4) How many books do you know whether you should burn $t$ ?

This sentence should have two readings, but only one of these is available. It can be uttered felicitously in a situation where the hearer is assumed to have a particular set of books in mind and the speaker wonders about the cardinality of that set. It cannot, on the other hand, be understood as asking whether there is a particular number of books (any books) that the hearer knows whether he should burn. In other words, (4) can have the existential reading exemplified in (5a) but not the degree reading in (5b):

(5) a. For what $\mathrm{n}$, there are $\mathrm{n}$-many books $\mathrm{X}$ such that you know whether you should burn $\mathrm{X}$ ? 
b. \#For what n, you know whether it should be the case that there be n-many books that you burn?

Where does this restriction come from? Cinque (1990) likens this case to (3): According to him the first reading can arise because in this case the how many-phrase is understood referentially, which allows it to be extracted as it can establish a relation with its trace via binding. The second reading is not available because in this case binding is not allowed and therefore long movement would have to occur, which is ruled out by syntax.

Referentiality (or related notions such as d-linking or specificity) have been at the heart of most syntactic theories of $w h$-islands. However, the exact nature of the notion 'referentiality' or 'd-linking' assumed has been always controversial (cf. Rullmann 1995, Cresti 1995, Szabolcsi \& Zwarts 1993, among others). The applicability of the notions of referentiality or specificity has been questioned, since even though wh-questions can range over individuals, it is unclear in what sense the wh-phrase itself can be understood as being able to have a referential index (as in Rizzi 1990) or a [+specific] feature (as in Starke 2001). The notion of d-linking is less problematic from a semantic point of view, as it simply requires that the range of felicitous answers to a question be limited to a contextually salient set. The problem with this notion however, as discussed in Kroch 1989, is that it fails to distinguish properly the island-sensitive and the island-insensitive items, as the first type usually also comes with a contextually defined domain restriction. Further, it has been argued (cf. Heycock 1995, Rullmann 1995, Cresti 1995, Fox 1995, Beck 1996) that the two readings of amount questions arise from the different scopal positions of the existential quantifier in them. But this means that to describe the difference between the wide and the narrow scope construal of amount questions, the notion of referentiality is not adequate.

Since the idea that referentiality or d-linking is the factor that enables moved elements to circumvent locality constraints is problematic, some scholars have tried to find alternative explanations. Cresti (1995) has offered the following proposal. Long movement is excluded by grammar, just as it was assumed in Rizzi 1990 and Cinque 1990 but locality constraints can be circumvented in some cases. This is because there is an extra position in embedded CPs with a filled specifier that can be used as an intermediate landing site for $w h$-movement. The trick is that this position can only host elements of type $e$, which is ensured by the following filter:

$$
\text { *[ст } \left.\left[{ }_{\delta} X\right][\text { ср } \ldots]\right] \text { where } X \text { is not of type } e
$$


Wh-islands in degree questions

Cresti's (1995) proposal can account for the fact that in (4), (5) and (6) the locality constraint can be circumvented as follows: In these cases that moved item is of type $e$, and therefore can use the extra intermediate landing site. Yet while Cresti's (1995) proposal does not rest on vague properties such as referentiality or d-linking, it is itself hardly explanatory. In particular, it is unclear why exactly elements of type $e$ should have the potential of using an extra landing site for movement. ${ }^{1}$ It seems then that the syntactic approach does not have a good answer for where the difference between (1a) and (1b) stems from. A second problem for the syntactic theory comes from cases of modal obviation, which will be discussed in Section 4.3. Examples such as (7b), given certain contexts, are significantly better than their non-modal counterpart.

(7) a. *How many pounds does the World Anti-Doping Agency know whether the boxers lost last year?

b. ?How many pounds does the World Anti-Doping Agency need to know whether the boxers lost last year?

These examples pose a serious challenge to this theory: if a syntactic locality constraint prohibits long movement in (7a), then why is the movement of a wh-phrase in (7b), which is arguably even longer, permitted? These facts argue strongly that the true explanation for $w h$-islands resides in the semantics and not the syntax of these questions. A second problematic issue for syntactic

1 A somewhat different structuring of the domain from that assumed by most syntactic approaches to weak islands is proposed by Beck (1996), who offers an analysis for a class of phenomena she calls intervention effects. Intervention effects occur when a wh-item would have to cross a quantifier at LF. Typical cases of this phenomenon are examples of ungrammatical scope-marking constructions in German.

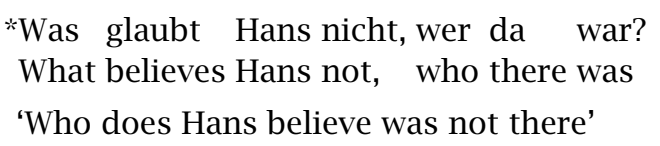

It is assumed that the embedded wh-word wer 'who' has to move to the position of the scope marker was at LF. But intervening negation and other quantifiers seem to block this movement. Beck (1996) proposes that examples such as (i) are ruled out by a constraint that prevents LF movement across an intervening quantifier. Beck (1996) argues that some cases of weak islands could be handled by the same constraint if we assume that these examples involve reconstruction at LF. The issue in this case is defining which items have to reconstruct and which do not, and whether one can give a definition of 'quantifier' that would rule out $w h$-islands, but not acceptable extractions from embedded questions. 
accounts is that not all interrogative verbs are created equal when it comes to inducing island effects. I come back to this issue in Section 3.

\subsection{Kroch (1989)}

Kroch (1989) has argued that the referentiality requirement is a pragmatic one, rather than constraining extraction syntactically. Syntactic extraction is thus freely allowed, but sometimes produces sentences that are pragmatically odd. Following Comorovski (1989), Kroch assumes that questions come with an existential presupposition. This presupposition is cancelable, and it does not constrain possible answers to the question. Rather, it acts as a requirement on the "askability" of the question, in that the speaker must presuppose the corresponding existential sentence in order to use the question felicitously. Further, the existential presupposition of questions introduces a discourse referent similarly to how declarative sentences with wide scope indefinites do. This discourse entity is uniquely identifiable, which he argues is shown by the fact that a question such as (8a) can be followed up by a statement (8b), which contains a pronoun that refers back to the discourse referent.

a. Who came?

b. Whoever he is better have had a good reason.

In the case of amount questions such as (4), what differentiates the entity (wide scope) reading from the amount (narrow scope) reading is that with the first reading the presupposition is more easily met given a suitable context, while the presupposition of the second reading is quite odd:

(9) a. There is an amount $n$ such that there are $n$-many books $X$ such that you know whether you should burn $X$.

b. \#There is an amount $n$, such that you know whether it should be the case that there be $n$-many books that you burn.

It is plausible that there is a particular set of books, such that someone can know whether to burn it. However, it is less plausible to know about a particular amount, whether one should burn that amount of books. Once we create contexts in which the presupposition of the degree reading is more plausible, the questions - Kroch argues - become more salient as well. He offers the following example: 
Wh-islands in degree questions

(10) a. How many points are the judges arguing about whether to deduct?

b. There is an amount $n$, such that the judges are wondering whether it should be the case that $n$-many points are deducted.

Kroch thus claims that the problem with $w h$-islands is a pragmatic, rather than a syntactic problem and that long movement of amount quantifier whphrases is not restricted in the syntax. However, he does not provide a formal analysis, only informal suggestions. ${ }^{2}$

\subsection{Fox \& Hackl (2007)}

Recently, Fox \& Hackl (2007) have proposed that negative degree islands arise because in these cases a maximally informative true answer cannot be found. This violates the presupposition introduced by Dayal (1996), according to which questions presuppose that they have a maximally informative true answer in the Hamblin/Karttunen denotation of the question, i.e., a true answer that entails all the other true answers (cf. also Beck \& Rullmann 1999). I will dub the presupposition of Fox \& Hackl (2007) and Dayal (1996) the Maximal Informativity Principle.

Maximal Informativity Principle

Any question presupposes that it has a maximally informative answer, i.e., a true answer which logically entails all the other true answers.

2 Szabolcsi \& Zwarts (1993) provide a general proposal for weak islands which is semantic in nature. They propose that each scopal expression (e.g., negation or quantifiers) can be thought of as a Boolean operation on a certain domain. Weak islands arise when the operations that the interveners need to perform on the domain of the wh-phrase are not defined, which they argue is what happens in the case of negation or universal quantification. Interestingly, they do not present an analysis for $w h$-islands, except for a promissory footnote (Szabolcsi \& Zwarts 1993: 248), in which they suggest that if one were to adopt Groenendijk \& Stokhof's (1984) analysis of interrogatives, then wh-expressions could be thought of as having universal force which would liken the cases of intervention by wh-expressions to the intervention effects created by universal quantifiers. Even if this promissory footnote could be expanded into a full fledged theory, Szabolcsi \& Zwarts 1993 would still be faced with the problem of modal obviation that was discussed above in connection with the syntactic proposals: If a certain wh-expression cannot take scope above a universal quantifier for principled reasons, it is hard to imagine why adding an extra universal modal would obviate this violation. Note that there are also good arguments that interrogatives should be constructed as existential, in accordance with Karttunen (1977), with strong exhaustivity encoded in the lexical semantics of the question embedding verb, cf. Heim (1994) and Beck \& Rullmann (1999). Existential quantifiers however do not cause intervention according to Szabolcsi \& Zwarts's (1993) theory. 
Here is a brief sketch of the analysis of Fox \& Hackl (2007). They assume what might be called the "classical approach" to degree predicates (cf. von Stechow 1984), according to which degree predicates denote functions that are monotonic. Given this, the informal logical form for a negative degree question such as (12a) below is (12b). The presupposition induced by the Maximal Informativity Principle amounts to the claim that among all the true statements of the form John did not drive at least d-fast, there is one that entails all the others.

a. *How fast didn't John drive?

b. For what degree $d$, John did not drive at least $d$-fast?

For any $d, d^{\prime}$, with $d \leq d^{\prime}$, the proposition that John didn't drive $d$-fast entails the proposition that John didn't drive $d^{\prime}$-fast. Therefore the maximally informative true answer, if it exists, must be based on the smallest degree $\mathrm{d}$ such that John's speed was not d or more than d. Suppose that John's exact speed was 4omph. Then for any $d>40$, John did not drive $d$-fast; but is there a smallest $d$ such that John did not drive $d$-fast, i.e., a smallest $d$ above 40? This depends on whether the scale itself is dense. Fox \& Hackl (2007) argue that it is in general a property of grammar that it treats scales as dense:

Universal Density of Measurement (UDM):

All scales are dense, i.e., for any two degrees $d_{1}$ and $d_{2}$ in a given scale, there is a degree $d_{3}$ between $d_{1}$ and $d_{2}$ :

$$
\forall d_{1} \forall d_{2}\left(\left(d_{1}<d_{2}\right) \rightarrow\left(\exists d_{3} d_{1}<d_{3}<d_{2}\right)\right) .
$$

Given the UDM, there cannot be a smallest degree such that John did not drive that fast: for any degree $40+\epsilon$, however small $\epsilon$ is, there is another degree $40+\epsilon^{\prime}$ strictly between 40 and $40+\epsilon$. Therefore it is a logical fact that the presupposition that there be a maximally informative true answer can never be met. As a consequence, for any answer, asserting that it is the maximally informative true answer equals asserting a contradiction.

The condition that there be a maximally informative true answer is somewhat similar to the presupposition that Kroch attributes to questions that there exists a "uniquely identifiable" entity of which the property described in the question holds, though it places a much weaker requirement on the context. If there is a uniquely identifiable discourse referent in the context to which the true answer ascribes some property, then there will also be a maximally informative true answer in the context set. The implication is not valid in the other direction though: Although from the availability of 
Wh-islands in degree questions

a maximally true answer it follows that there be a unique entity of which the maximally informative true answer holds, it does not follow that this entity should be an identifiable discourse referent in a pragmatic sense. On the other hand, when negative degree questions cannot have a maximally informative true answer, the presupposition that there is a uniquely identifiable discourse referent is also not met. But note that Fox \& Hackl's (2007) proposal goes much further than the account sketched by Kroch in that it provides an explanation for why in some cases it is not possible that there be a uniquely identified discourse referent, while Kroch simply stipulated it.

\subsection{An interval semantics for degrees and context sensitive MIP}

The assumption of Fox \& Hackl (2007) that scales are dense is certainly natural when we talk about speed or height. But, as Fox and Hackl themselves point out, there are scales which we intuitively don't treat as dense, consider for instance the following contrast:

(14) a. How many children does John have?

b. *How many children doesn't John have?

Naturally we assume children to be discrete entities. But if maximal informativity was evaluated with respect to a discrete scale of degrees, then (14b) would be predicted to have a most informative true answer: e.g., if John has exactly 3 children, the most informative true answer to (14b) would be that he does not have 4 children, since not having 4 children entails not having 5,6 or any higher number of children. Therefore in this case the question should have a most informative answer, and should be acceptable, contrary to fact.

Fox \& Hackl's (2007) approach avoids this potential problem in the following way: in order to decide whether a degree question is grammatical or not, grammar abstracts away from lexical or contextual knowledge (e.g., the knowledge that the number of children someone has is an integer) that could impose a granularity restriction on the scale of degrees and only makes use of a purely logical notion of entailment defined on the scale that is made available by grammar, which is dense. So Fox and Hackl do not only need to claim that all scales are dense; they also need to assume a modular system in which some semantic and pragmatic processes operate in isolation and are blind to contextual information, in particular to possible contextual restrictions on the range of variables. Fox \& Hackl's (2007) explicit goal is to 
challenge certain widely accepted assumptions regarding the relationship between grammar, pragmatic processes, lexical meaning and contextual factors. Nevertheless, Abrusán \& Spector (2011) have challenged Fox \& Hackl's (2007) assumption that the Universal Density of Measurement hypothesis is needed to explain the ungrammaticality of negative degree islands. Instead, they argue that it is possible to account for the negative island cases by accepting the Maximal Informativity Principle, but combining it with the assumption (originally proposed by Schwarzschild \& Wilkinson 2002, cf. also Heim 2006) that degree expressions range over intervals.

One of the main empirical reasons for the proposal that degree questions should range over intervals comes from the observation that an interval-based reading has to be assumed for the correct interpretation of certain embedded degree questions, such as (15b) below, uttered just after the discourse given in (15a):

(15) a. John and Peter are devising the perfect Republic. They argue about speed limits on highways. John believes that people should be required to drive at a speed between $50 \mathrm{mph}$ and $70 \mathrm{mph}$. Peter believes that they should be required to drive at a speed between 5omph and 8omph. Therefore ...

b. John and Peter do not agree on how fast people should be required to drive on highways.

The example in (15b) can be judged true in the context given in (15a). Following remarks by Sharvit (2002) it can be assumed that for $X$ and $Y$ to disagree on a given question $\mathrm{Q}$, it must have at least one potential answer ${ }^{3} \mathrm{~A}$ to which $\mathrm{X}$ and $\mathrm{Y}$ do not assign the same truth-value. This means that for John and Peter to disagree on how fast people should be required to drive, i.e., for (15b) to be true, there must be at least one answer to How fast should people be required to drive on highways? about which John and Peter disagree. What is important is that in the context described in (15a), John and Peter do not actually disagree about the minimal permitted speed: in fact they agree on the truth value of every proposition of the form People should be required to drive at least $d$-fast. Therefore the 'standard' view of degree questions

3 I will assume that an answer to a degree-question of the form [How $\phi(I)]$ is a proposition that belongs to the Hamblin-set of the question, i.e., a proposition that can be expressed as $\phi(I)$, for some interval $I$. Many propositions that can intuitively serve as answers are not in this set. 
Wh-islands in degree questions

predicts (15b) to be false in the above context, contrary to fact, which shows that the standard view is insufficient. The interval-based analysis on the other hand straightforwardly accounts for this truth-value judgment.

Following Schwarzschild \& Wilkinson (2002) and Heim (2006), Abrusán \& Spector (2011) assume that degree adjectives establish a relation between individuals and intervals:

a. $\llbracket$ tall $\rrbracket=\lambda I_{<d, t>} . \lambda x_{e} . x$ 's height $\in I$

b. $\llbracket J o h n$ is $I$-tall $\rrbracket=1$ iff John's height $\in I \quad$ where $I$ is an interval

c. A set of degrees $D$ is an interval iff

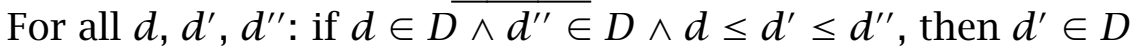

The interpretation of a degree question is then as follows:

$\llbracket$ How tall is John? $\rrbracket^{w}=$

$$
\begin{aligned}
& \lambda p . \exists I\left[I \in D_{I} \wedge p=\lambda w^{\prime} . \text { John's height } \in I \text { in } w^{\prime}\right] \\
& \text { 'For what interval I, John's height is in that interval?' }
\end{aligned}
$$

Given the interval-based semantics, (15b) now means that for at least one interval of speeds I, John and Peter do not agree on the truth-value of People should be required to drive at a speed included in I. And this is indeed the case in the scenario given in (15a) - namely, John believes that people should be required to drive at a speed contained in $I=$ [50; 70], while Peter thinks this is not so. ${ }^{4}$

Having observed that it is necessary to introduce intervals to capture the full range of readings of degree questions, Abrusán \& Spector (2011) show that the assumption that degree questions range over intervals can also explain the cases of negative island violations such as (12a) above. In their system this question receives the following interpretation:

(18) For what interval $I$ of degrees of speed, John's speed was not in $I$ ?

First, let's show that (18) has a true answer that entails all the true answers if and only if John's speed was o. Let $s$ be John's speed, distinct from o. The set of intervals such that $s$ is not in them consists of a) all the intervals strictly below $s$, and b) all the intervals strictly above $s$. The set of all the true answers to (18) is the set of answers based on intervals that do not contain $s$ (where an answer is said to be 'based' on an interval $I$ if it expresses the

4 Notation: Square brackets indicate the inclusion of the endpoint in an interval, and round brackets indicate the exclusion of the endpoint. 
proposition that John's speed was not in I). Crucially, any answer based on an interval above $s$ fails to entail an answer based on an interval strictly below $s$, and vice versa. So (18) has a true answer that entails all the true answers if and only if John's speed was o, which in turn means that (18) can be felicitous only when it is common knowledge that John's speed was o, (i.e., equivalently, that his speed was not included in $(0 ;+\infty))$. But then the most informative answer, namely the proposition that John's speed is not included in $(0 ;+\infty)$, is in fact already entailed by the common ground. Abrusán \& Spector (2011) argue that a maximally informative answer must not only be a true answer that entails all the true answers, but must also be contextually informative. However, if it is already known in the context that John's speed was zero, this proposition is not a maximally informative answer after all. In order to capture the notion of maximal informativity relative to context, Abrusán \& Spector (2011) propose to modify the MIP slightly along the following lines:

(19) a. Definition: An answer A to a question Q is a Maximally Informative Answer to $\mathrm{Q}$ in a world $\mathrm{w}$ if $\mathrm{A}$ is true in $\mathrm{w}$ and entails all the answers to $Q$ that are true in $w$.

b. Maximal Informativity Principle (MIP).

A question $Q$ presupposes that for every world w compatible with the context, there is an answer A to Q such that:

- A is the maximally informative answer to $\mathrm{Q}$ in $\mathrm{w}$.

- For at least one other world w' compatible with common knowledge, A is not the maximally informative answer in w'.

In this paper I will assume that this modified version of the MIP is correct. ${ }^{5}$

\subsection{Preview of this paper}

This paper proposes that Fox \& Hackl's (2007) idea according to which the unacceptability of negative degree islands results from the maximal informativity requirement can also explain why wh-islands arise with degree

5 As noted by an anonymous reviewer, one consequence of this modification of the MIP is that the contradiction derived does not fall strictly under Gajewski's (2002) theory, according to which sentences that are analytical in virtue of their logical constants alone are ungrammatical. This is because Gajewski's theory, as stated, has no room for contextsensitivity. Various other data (cf. Fox \& Hackl 2007, Abrusán 2011) suggest that Gajewski's condition needs to be loosened somewhat, and accommodate certain restrictions about alternatives, presuppositions and context. I discuss this issue in more detail in Abrusán (in preparation). 
Wh-islands in degree questions

questions. I also argue that verbs fall into different subclasses with respect to the question whether they introduce weak islands or not. Degree questions with responsive predicates such as know can never receive a maximally informative answer, and are thus unacceptable in any context. Degree questions with inquisitive predicates such as wonder however are not derived to be ungrammatical, nevertheless they are predicted to have a most informative true answer only in very special and unnatural contexts, which renders them pragmatically odd. In the first case the unacceptability of $w h$-islands can be derived both by using the classical and the interval based degree semantics. I discuss the examples of modal obviation in Section 4.3. In sum, this paper suggests that Kroch's (1989) informal account of $w h$-islands was on the right track, and provides an explanation for why in certain cases most informative answers are impossible or contextually restricted.

A note on terminology: if the presupposition that there be a maximally informative true answer cannot be met, then for any answer, asserting that it is the maximally informative true answer equals asserting a contradiction. Following standard terminology, we can call the assertion of the most informative true answer together with the negation of all the alternatives that are not logically entailed by it the complete (or exhaustive) answer. Thus, another way of phrasing that no maximally informative true answer can be found is that the complete (or exhaustive) answer expresses a contradiction. I will use these ways of describing the problem interchangeably throughout in the paper.

\section{Wh-islands and the semantics for degree questions}

Question embedding predicates differ along various dimensions. One empirical difference is with respect to the so-called quantificational variability effect, the phenomenon of modifying interrogative verbs by a quantificational adverb such as mostly. Contrast (20) with (21):

(20) John mostly knows/told us/remembered/guessed/forgot which girls came to the party.

(21) *John mostly wondered/asked/investigated which girls came to the party.

This difference splits the domain of interrogative verbs into two classes that Lahiri (2002) calls responsive (know-class) and rogative (wonder-class) 
verbs. ${ }^{6}$ The group of responsive predicates contains Karttunen's (1977) verbs of retaining and acquiring knowledge as well as verbs of communication, decision, conjecture and opinion. Rogative predicates include inquisitive verbs, as well as verbs of relevance and dependency.

(22) Responsive predicates (know-class)

Verbs of retaining knowledge know, be aware, recall, remember, forget

Verbs of acquiring knowledge learn, notice, find out

Verbs of communication tell, show, indicate

Verbs of decision decide, determine, specify, agree on

Opinion verbs be certain about, be convinced about

(23) Rogative predicates (wonder-class)

Inquisitive verbs

Verbs of relevance

Verbs of dependency wonder, ask, investigate, examine, consider

matter, be relevant, be important, care

depend on, be related to, have an influence on, make a difference to

(NB: In what follows I will not discuss verbs of relevance and dependency because these have grammatical properties that make them unsuitable to test for $w h$-island effects: the former require a cleft-structure that is independently an island inducer, the latter relate two questions.)

Interestingly, there is a difference among question taking verbs with respect to how strongly they induce a weak island effect, and this difference correlates to some extent with the above classification. While responsive predicates tend to induce very strong island effects, questions formed with inquisitive verbs seem to create a weaker effect, at least comparatively, as shown by examples (24)-(26). ${ }^{7}$

6 Related but somewhat different classifications have been proposed by Groenendijk \& Stokhof (1982, 1984) and Ginzburg (1995). It has also been suggested that different classes of interrogatives might require complements of a different semantic type, e.g., according to Lahiri (2002) rogative predicates are fundamentally proposition taking, i.e., they are of type $<<\mathrm{s}, \mathrm{t}>, \mathrm{b}>$, while wonder-type predicates are of the type $<<<\mathrm{s}, \mathrm{t}>, \mathrm{t}>\mathrm{b}>$, that is they take genuine question-complements. In this paper I depart from these assumptions slightly and assume that both types take question denotations as complements and the differences follow from their lexical semantics. This difference is only meant to simplify the discussion, and is not crucial in deriving the $w h$-island effect.

7 Example (24) was contributed by Pranav Anand (pc). 
Wh-islands in degree questions

(24) a. ?How many inches of legroom are the airline executives considering whether we can remove from economy class cabins (without people noticing)?

b. *How many inches of legroom did the airline executives find out whether we can remove from economy class cabins (without people noticing)?

(25) a. ?How much wine are scientists investigating/examining whether it is useful to drink in order to stay healthy?

b. *How much wine did scientists discover whether it is useful to drink in order to stay healthy?

(26) a. ?How many kilograms are the boxers wondering whether it is worth losing next year (in order to have a better chance to win)?

b. *How many kilograms did the boxers forget/realize/tell you whether it was worth losing last year?

The (a) sentences in the examples above were judged to be markedly better than the (b) examples by my informants. Notice also that the (a) and (b) examples do not differ with respect to the "specificity" or "referentiality" of the degree phrase and therefore it is unclear how the syntactic accounts mentioned above could capture it. This paper proposes that the difference follows from principled reasons: inquisitive verbs have a more complex lexical semantics than responsive verbs, namely they contain an extra intentional layer. It is due to this fact that inquisitive verbs induce weaker island effects.

This section examines $w h$-islands that arise with know-class predicates and shows that the Maximal Informativity Principle is violated in these cases, which predicts that they should be unacceptable. Questions formed with wonder-class predicates will be examined in Section 4 .

\subsection{Movement from embedded whether questions}

I assume that a question denotes a set of possible answers ${ }^{8}$ to it (cf. Hamblin 1973), which using the notation introduced in Karttunen 1977 can be defined as follows:

(27) 【Who left? $\rrbracket^{w}=\lambda p \cdot \exists x\left[\operatorname{person}(x)(w) \wedge p=\lambda w^{\prime} \cdot x\right.$ leaves in $\left.w^{\prime}\right]$

8 As usual, the term answer is used in a narrow, technical sense: an answer to a question of the form $\left[W h_{D} \cdot \phi\left(t_{\mathrm{wh}}\right)\right]$ is a proposition that can be expressed as $\phi(a)$, for some $a \in D$. 
I will refer to this denotation as the $\mathrm{H} / \mathrm{K}$ denotation.

In what follows I first discuss examples with the question verb know. In Section 3.2 the analysis proposed here will be extended to other examples of responsive verbs. The main features of the lexical semantics of the question embedding verb know that are important for us can be represented as follows ${ }^{9}\left(\mathrm{Q}_{\mathrm{H}}(\mathrm{w})\right.$ stands for the $\mathrm{H} / \mathrm{K}$-denotation of an interrogative):

(28) know $(w)\left(x, Q_{\mathrm{H}}(w)\right)$ is true iff $\forall p \in Q_{H}(w)$ and $\forall w^{\prime} \in \operatorname{Dox}_{x}(w)$, if $p(w)=1, p$ is true in $w^{\prime}$ and if $p(w) \neq 1, \neg p$ is true in $w^{\prime}$. where $\operatorname{Dox}_{x}(w)=\left\{w^{\prime} \in W: x\right.$ 's beliefs in $w$ are satisfied in $\left.w^{\prime}\right\}$

There are two aspects of the lexical representation above that are important for the present analysis. The first is that ' $x$ knows whether $p$ ' is equivalent to ' $x$ knows that $p \vee x$ knows that $\neg p$ '. This is indeed one of the crucial properties that will lead to the island violations with degree questions. The second important property of the lexical meaning for question embedding know is that it requires a (strongly) exhaustive reading of the embedded interrogative complement. This property is inert in the case of embedded whether complements, because these are strongly exhaustive by nature, however it will play a role in Section 3.5.

The meaning of (29a) is the set of propositions defined by (29b):

(29) a. Who does Mary know whether she should invite?

b. $\lambda q . \exists x[\operatorname{person}(x) \wedge$

$$
\begin{aligned}
& q=\lambda w . \operatorname{knows}(w) \text { (Mary, } \lambda p \cdot[ \\
& p=\lambda w^{\prime} . \text { she }_{m} \text { should invite } x \text { in } w^{\prime} \vee \\
& \left.\left.\left.p=\lambda w^{\prime} . \text { she }_{m} \text { should not invite } x \text { in } w^{\prime}\right]\right)\right]
\end{aligned}
$$

Let's suppose that the domain of individuals in the discourse is \{Bill, John, Fred\}, and let's restrict ourselves for a moment to the set of propositions about singular individuals that describes, i.e., the set in (30a). We might also represent this set of propositions in a semi-formal notation as in (30b):

(30) a. \{ that Mary knows whether she should invite Bill, that Mary knows whether she should invite John, that Mary knows whether she should invite Fred \}

9 This representation is equivalent to analyzing know as true belief. This should not be taken to mean that I assume that know is indeed equivalent to true belief, as there might well be further aspects to the lexical semantics of know, not represented here. The claim being made is only that the above mentioned ingredients are sufficient to derive the oddness of wh-islands. 
Wh-islands in degree questions

b. $\left\{\forall w^{\prime} \in \operatorname{Dox}_{M}(w)\right.$,

(if $\operatorname{invB}$ in $w, \operatorname{inv} B$ in $\left.w^{\prime}\right) \wedge$ (if $\neg \operatorname{inv} B$ in $w, \neg i n v B$ in $w^{\prime}$ ),

$\forall w^{\prime} \in \operatorname{Dox}_{M}(w)$,

(if invJ in $w$, invJ in $w^{\prime}$ ) $\wedge$ (if $\neg i n v J$ in $w$, $\neg i n v J$ in $w^{\prime}$ ),

$\forall w^{\prime} \in \operatorname{Dox}_{M}(w)$,

(if invF in $w$, invF in $\left.w^{\prime}\right) \wedge$ (if $\neg$ invF in $w, \neg i n v F$ in $w^{\prime}$ ) \}

where $i n v X$ in $w$ is a notational shorthand for Mary should invite $X$ in $w$

An exhaustive (complete) answer to a question Q is the assertion of some proposition $p$ in $\mathrm{Q}$ together with the negation of all the remaining alternatives in $\mathrm{Q}$ that are not entailed by $p$ :

(31) Exhaustive (complete) answer

$\operatorname{Exh}(\mathrm{Q})(w)=\iota p\left[p \in \mathrm{Q} \wedge p(w) \wedge \forall p^{\prime} \in \mathrm{Q}\left[p \nsubseteq p^{\prime} \rightarrow \neg p^{\prime}(w)\right]\right]$

Suppose that we assert Mary knows whether she should invite Bill as an answer to the question in (29). The statement that this answer is the complete answer means that we assert that the rest of the alternative propositions in $\mathrm{Q}$ which are not entailed by it are false: i.e., we assert that Mary knows whether she should invite Bill and that she does not know whether she should invite John and that she does not know whether she should invite Fred:

$$
\begin{aligned}
& \text { Mary knows whether she should invite Bill } \\
& \forall w^{\prime} \in \operatorname{Dox}_{M}(w) \text {, } \\
& \text { if } \operatorname{in} v B \text { in } w \text {, invB in } w^{\prime} \wedge \text { if } \neg \operatorname{in} v B \text { in } w \text {, } \neg \operatorname{in} v B \text { in } w^{\prime} \text {, } \\
& \text { and } \exists w^{\prime} \in \operatorname{Dox}_{M}(w) \text {, } \\
& \text { (invJ in } \left.w \wedge \neg i n v J \text { in } w^{\prime}\right) \vee\left(\neg i n v J \text { in } w \wedge i n v J \text { in } w^{\prime}\right) \text {, } \\
& \text { and } \exists w^{\prime} \in \operatorname{Dox}_{M}(w) \text {, } \\
& \text { (invF in } \left.w \wedge \neg \text { invF in } w^{\prime}\right) \vee\left(\neg i n v F \text { in } w \wedge i n v F \text { in } w^{\prime}\right)
\end{aligned}
$$

As long as we restrict ourselves to answers about singular individuals no problem arises with complete answers to the question in (29): the meaning expressed above is coherent. This is because the alternatives in the question denotation are independent from each other: e.g., whether or not Bill is invited in the actual world is independent from whether or not Fred is invited.

The situation does not change if we add possible answers about plural individuals as long as we can interpret the embedded predicate distributively. Following Link (1983) I will assume that the distributive interpretation of 
predicates is derived via a distributive operator Dist. Further, this operator incorporates a homogeneity presupposition, which derives the "all or nothing” inference of pluralities (cf. Löbner 1985, Schwarzschild 1996, Beck 2001, Gajewski 2005).

$$
\operatorname{Dist}(P)=\lambda x:[\forall y \in x P(y)] \text { or }[\forall y \in x \neg P(y)] . \forall y \in x P(y)
$$

Given the homogeneity presupposition, we derive that an utterance such as I didn't see the boys gives rise to an inference that I did not see any of the boys: The utterance presupposes that I either saw all the boys or I did not see any of them, and it will assert that it is false that I saw each of the boys. The combination of the presupposition and the assertion results in the inference that I did not see any of the boys.

If we allow the question to range over plural individuals, the informal representation of the question denotation will be as follows (where the subscript $\mathrm{D}$ indicates that the distributive operator is applied to the predicate):

(34) \{ that Mary knows whether she should invite Bill, that Mary knows whether she should invite John, that Mary knows whether she should invite Fred, that Mary knows whether she should invite $\mathrm{D}_{\mathrm{D}}$ John+Bill,

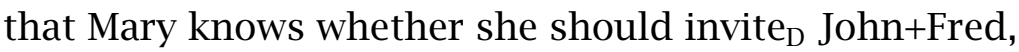

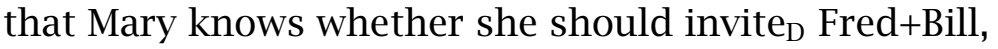
that Mary knows whether she should invite ${ }_{\mathrm{D}}$ John+Fred+Bill $\}$

Now suppose the actual true answer to (29) is that Mary knows whether she should invite John+Bill, where John+Bill is understood to denote a plural individual. The proposition expressed by this answer will entail the propositions that Mary knows whether she should invite Bill and that Mary knows whether she should invite John if the predicate invite is interpreted distributively. Here is why. Contrast the schematic representations of the two propositions below:

a. $\forall w^{\prime} \in \operatorname{Dox}_{M}(w)$

(if $i n v_{\mathrm{D}} A+B$ in $w, i n v_{\mathrm{D}} A+B$ in $\left.w^{\prime}\right) \wedge$

(if $\neg i n v_{\mathrm{D}} A+B$ in $w, \neg i n v_{\mathrm{D}} A+B$ in $w^{\prime}$ )

b. $\forall w^{\prime} \in \operatorname{Dox}_{M}(w)$,

(if $\operatorname{inv} A$ in $w, \operatorname{inv} A$ in $\left.w^{\prime}\right) \wedge$

(if $\neg \operatorname{inv} A$ in $w, \neg i n v A$ in $w^{\prime}$ ) 
Wh-islands in degree questions

Since $i n v_{\mathrm{D}} A+B$ entails $i n v A$, (given the distributive operator) and $\neg i n \nu_{\mathrm{D}} A+B$ entails $\neg i n v A$ (given the homogeneity presupposition on the distributive operator), the proposition in (35a) entails the proposition (35b). The exhaustification of the proposition that Mary knows whether she should invite John+Bill in the present context will consist of negating the proposition that Mary knows whether she should invite Fred, and all the pluralities involving Fred. These propositions are represented in italics below.

(36) that Mary knows whether she should invite Bill, that Mary knows whether she should invite John, $\neg$ that Mary knows whether she should invite Fred, that Mary knows whether she should invite ${ }_{\mathrm{D}}$ John+Bill, $\neg$ that Mary knows whether she should invite ${ }_{D}$ John+Fred, $\neg$ that Mary knows whether she should invite ${ }_{D}$ Fred+Bill, $\neg$ that Mary knows whether she should invite ${ }_{D}$ John + Fred Bill $^{1 \circ}$

As the negation of these propositions is consistent with asserting the proposition that Mary knows whether she should invite John+Bill, we see that a maximally informative true answer can be found even in the cases where the wh-question is allowed to range over plural individuals. ${ }^{11}$

\subsection{Weak islands with responsive predicates: a classical degree seman- tics}

Assume that degree predicates such as fast or tall denote a relation between individuals and degrees which is monotone decreasing with respect to the degree argument. This ensures that being d-tall is equivalent to being d-tall or more (cf. von Stechow 1984 and others). Observe now the question below, and its logical representation ${ }^{12}$ :

10 Note that it does not follow from $\neg$ that Mary knows whether she should invite ${ }_{D}$ John+Fred+Bill that $\neg$ that Mary knows whether she should invite ${ }_{D} J o h n+$ Bill.

11 Sigrid Beck notes that this predicts that non-distributive predicates in similar whether questions should be unacceptable. This prediction seems to be borne out:

(i) ???Who does Mary know whether the soccer players outnumber?

(answer: The tennis players).

12 Note that tense on the embedded verb tends to create strong islands (cf. Manzini 1992, among others). It is for this reason that there needs to be a modal in the embedded clause, since this allows the verb to be in the infinitive and thus we can be reasonably sure that we are indeed looking at a case of a weak island. 
(37) a. *How tall does Mary know whether she should be?

b. $\lambda q . \exists d\left[d \in D_{d} \wedge q=\lambda w\right.$. $\operatorname{knows}(w)$ (Mary, $\lambda p .[$

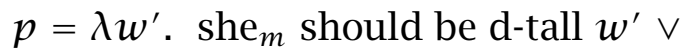

$p=\lambda w^{\prime} . \neg$ she $_{m}$ should be d-tall in $\left.\left.\left.w^{\prime}\right]\right)\right]$

'For what $d$, Mary knows whether she should be (at least) $d$-tall?'

Importantly, the answers to this question do not entail each other logically. This is because the true answer could be based either on the fact that Mary has knowledge about a certain degree of height that she should be at least that tall, or on the fact that she has knowledge about a certain height that she is not required to be at least that tall. These two contexts would enforce entailment relationships in two opposite directions: If Mary knows that she should be $n$-tall, then for all degrees smaller than $n$, she knows that she should be $n$ tall. On the other hand, if she knows that she is not required to be $n$-tall, then for all degrees greater than $n$ she knows that she is not required to be that tall. Since the truth of each of the alternatives could be based on either the positive or the negative fact, there is no logical entailment among the question alternatives: from the truth of the proposition that Mary knows whether she should be $n$ tall it neither follows that she knows that she should be $n+1$ tall, nor that she knows that she should be $n-1$ tall. This suggests that there should be no obstacle to finding a maximally informative true answer and form a non-contradictory complete answer. The problem is, however, that in any context the actual true answer has to be based on facts that will make a complete answer contradictory.

Suppose that we were to choose a potential maximally informative true answer among the question alternatives below:

(38) a. \{ that Mary knows whether her height should be $d_{1}$, that Mary knows whether her height should be $d_{2}$, that Mary knows whether her height should be $d_{3}$, ... etc, for all degrees $d$ in $D \quad$ \}

b. $\left\{\forall w^{\prime} \in \operatorname{Dox}_{M}(w), \quad\left[\right.\right.$ if $\left.d_{1}(w)=1, d_{1}\left(w^{\prime}\right)=1\right] \wedge$

[if $\neg d_{1}(w)=1, \neg d_{1}\left(w^{\prime}\right)=1$ ],

$\forall w^{\prime} \in \operatorname{Dox}_{M}(w), \quad\left[\right.$ if $\left.d_{2}(w)=1, d_{2}\left(w^{\prime}\right)=1\right] \wedge$

[if $\neg d_{2}(w)=1, \neg d_{2}\left(w^{\prime}\right)=1$ ],

$\forall w^{\prime} \in \operatorname{Dox}_{M}(w), \quad\left[\right.$ if $\left.d_{3}(w)=1, d_{3}\left(w^{\prime}\right)=1\right] \wedge$

[if $\left.\left.\neg d_{3}(w)=1, \neg d_{3}\left(w^{\prime}\right)=1\right] \quad\right\}$

where $d_{n}(w)$ is a notational shorthand for Mary's height should be $d_{n}$ in $w$. 
Imagine that we were to state Mary knows whether her height should be $d_{2}$ as a complete answer. A complete answer equals the assertion of the most informative true answer together with the negation of all the alternatives that are not logically entailed by the most informative true answer. In this case, the complete answer could be represented as follows:

$$
\begin{aligned}
& \forall w^{\prime} \in \operatorname{Dox}_{M}(w), \\
& {\left[\underline{\text { if } d_{2}(w)=1, d_{2}\left(w^{\prime}\right)=1}\right] \wedge\left[\text { if } \neg \mathbf{d}_{\mathbf{2}}(\mathbf{w})=\mathbf{1}, \neg \mathbf{d}_{\mathbf{2}}\left(\mathbf{w}^{\prime}\right)=\mathbf{1}\right]} \\
& \text { and for any } d^{\prime}<d_{2} \text {, } \\
& \exists w^{\prime} \in \operatorname{Dox}_{M}(w), \\
& \left(\underline{\left.d^{\prime}(w)=1 \wedge \neg d^{\prime}\left(w^{\prime}\right)=1\right)} \vee\left(\neg d^{\prime}(w)=1 \wedge d^{\prime}\left(w^{\prime}\right)=1\right)\right. \\
& \text { and for any } d^{\prime \prime}>d_{2} \text {, } \\
& \exists w^{\prime} \in \operatorname{Dox}_{M}(w) \text {, } \\
& \left(d^{\prime \prime}(w)=1 \wedge \neg d^{\prime \prime}\left(w^{\prime}\right)=1\right) \vee\left(\neg \mathbf{d}^{\prime \prime}(\mathbf{w})=\mathbf{1} \wedge \mathbf{d}^{\prime \prime}\left(\mathbf{w}^{\prime}\right)=\mathbf{1}\right)
\end{aligned}
$$

Crucially, the complete answer is computed based on logical entailment and not contextual entailment. But, given the disjunction in the representation of the whether-clause, the truth of the answer in (39) will be based either on Mary's true belief about some degree such that she has to be that tall, or on Mary's true belief about some degree such that she is not required to be that tall. Imagine a context in which the first is the case. In such a context, for any $d^{\prime}$ if $d_{2}>d^{\prime}$, the proposition that Mary knows whether she should be at least $d_{2}$-tall will entail that Mary knows whether she should be at least $d^{\prime}$-tall. Thus e.g., the answer that Mary knows whether she should be at least $185 \mathrm{~cm}$ tall will entail that for any degree below 185, she knows whether she should be that tall. Therefore the assertion that the chosen proposition is the maximally informative answer is a contradiction, unless $d_{2}=0$. (The source of the contradiction is underlined in the example above.) In a context in which it was known that the true answer for the question is based on Mary's true belief about some degree such that she is not required to be that tall, for any $d^{\prime \prime}, d^{\prime \prime}>d_{2}$, the proposition that Mary knows whether she should be at least $d_{2}$-tall will entail that Mary knows whether she should be at least $d^{\prime \prime}$-tall. Therefore, if Mary knows whether she should be at least $185 \mathrm{~cm}$ tall will entail that for any degree above 185, she knows whether she should be that tall. This means that in this context she knows that she does not have to be 185 or more. Again, assuming that the domain of degrees is infinite, the statement that Mary knows whether her height should be $d$ is the complete answer to the question will be a contradiction. (The source of the contradiction is shown in boldface in the example above.) 
This means that the complete answer to the question will in effect express a contradiction in any context except the one which entails that Mary knows whether she should be tall to a o degree. In this case however the question is not informative. Following Abrusán \& Spector's (2011) amendment according to which a maximally informative answer must not only be a true answer that entails all the true answers, but must also be contextually informative, the question in (37) is ruled out as a violation of the MIP.

Notice that the problem observed arose from two properties of know. The first is that ' $x$ knows whether $p$ ' is equivalent to ' $x$ knows that $p \vee x$ knows that $\neg p$ '. Because of this property, the alternatives in the question denotation do not entail each other. The second property is that know that $p$ is upward monotonic, i.e., if $p$ entails $q$, knowing that $p$ entails knowing that $q$, at least in the cases where the subject can be expected to know that $p$ entails $q$. Given these two properties in any given context selecting one of the alternatives as the most informative complete answer will lead to a contradiction, as we have seen above. For this reason, the analysis presented here goes through for all question embedding predicates for which the two properties described above hold: this is true for the set of rogative predicates e.g., recall, notice, find out, etc, but not true for responsive predicates such as wonder.

\subsection{An interval semantics for degree questions}

Suppose now that we follow Schwarzschild \& Wilkinson (2002), and Abrusán \& Spector (2011) in assuming that degree adjectives establish a relation between individuals and intervals. ${ }^{13}$ According to this view the logical form of a degree question such as (40) below corresponds to the following:

(40) a. How tall is Mary?

b. For what interval $I$ of degrees of height, Mary's height is in $I$ ?

Now let $h$ be Mary's height. Clearly, any answer based on an interval that includes $h$ is a true answer; furthermore, the proposition that Mary's height belongs to a given interval $I_{1}$ entails the proposition that Mary's height belongs to $I_{2}$, for any $I_{2}$ that includes $I_{1}$. Consequently, the proposition that

13 Schwarzschild (2004), Heim (2006) and Abrusán \& Spector (2011) have argued that the interval reading is not basic, but derived by a point-to-interval operator (П). Nevertheless, it can be shown that even adopting a $\Pi$ operator the question above has no reading under which the Maximal Informativity Principle is not violated. 
Wh-islands in degree questions

Mary's height belongs to the interval $[h, h]$ (i.e., is $h$ ) expresses a true answer that entails all the other true answers, hence is the maximally informative answer.

Assuming the interval semantics to degree expressions, the $\mathrm{H} / \mathrm{K}$ denotation of a question with movement of the degree expression out of the embedded whether complement is as follows:

(41) a. *How tall does Mary know whether she should be? (in order to join the basketball team)

b. $\lambda q . \exists I\left[I \in D_{I} \wedge q=\lambda w\right.$. $\operatorname{knows}(w)$ (Mary, $\lambda p .[$

$$
\begin{aligned}
& p=\lambda w^{\prime} . \text { her }_{m} \text { height should be in } I \text { in } w^{\prime} \vee \\
& \left.\left.\left.p=\lambda w^{\prime} . \neg \text { her }_{m} \text { height should be in } I \text { in } w^{\prime}\right]\right)\right]
\end{aligned}
$$

We might represent this set informally, as in (42a) or semi-formally as in (42b): (Notice that for one to know that her height should not be in some interval I equals knowing that her height should not be in the complement of interval I in a given domain of degrees, which I represent as $\neg$ I.)

(42) a. \{ that Mary knows whether her height should be in $I_{1}$, that Mary knows whether her height should be in $I_{2}$, that Mary knows whether her height should be in $I_{3}$, ... etc, for all intervals in $\left.D_{I} \quad\right\}$

b. $\left\{\forall w^{\prime} \in \operatorname{Dox}_{M}(w), \quad\left[\right.\right.$ if $\left.I_{1}(w)=1, I_{1}\left(w^{\prime}\right)=1\right] \wedge$ [if $\neg I_{1}(w)=1, \neg I_{1}\left(w^{\prime}\right)=1$ ], $\forall w^{\prime} \in \operatorname{Dox}_{M}(w), \quad\left[\right.$ if $\left.I_{2}(w)=1, I_{2}\left(w^{\prime}\right)=1\right] \wedge$ [if $\neg d_{2}(w)=1, \neg I_{2}\left(w^{\prime}\right)=1$ ], $\forall w^{\prime} \in \operatorname{Dox}_{M}(w), \quad\left[\right.$ if $\left.I_{3}(w)=1, I_{3}\left(w^{\prime}\right)=1\right] \wedge$ [if $\neg I_{3}(w)=1, \neg I_{3}\left(w^{\prime}\right)=1$ ] $\}$ where $I_{n}(w)$ is a notational shorthand for Mary's height should be in $I_{n}$ in $w$.

Imagine now that we were to state Mary knows whether her height should be in $I_{1}$ as a complete answer. A complete answer is equal to the assertion of the most informative true answer together with the negation of all the alternatives that are not entailed by the most informative true answer. Now let's take 3 intervals: interval 1, interval 2 which is fully contained in 1 and interval 3 which is fully contained in the complement of 1 : 


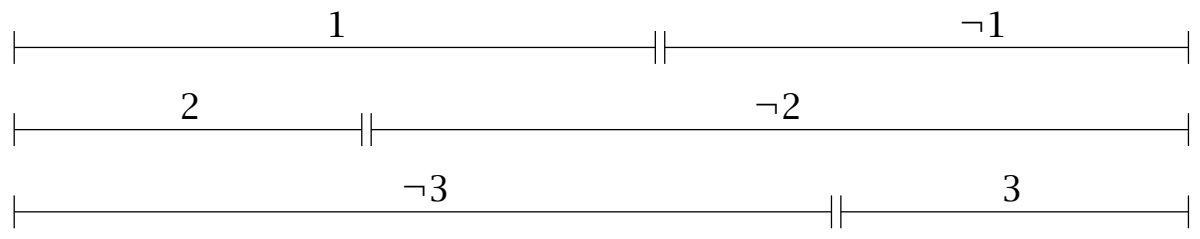

The propositions that Mary knows whether her height should be in $I_{1}$ and that Mary knows whether her height should be in $\mathrm{I}_{2}$ and that Mary knows whether her height should be in $I_{3}$ do not entail each other. Thus, asserting that Mary knows whether her height should be in $I_{1}$ as a complete answer would amount to asserting the conjunction that she knows whether her height should be in $I_{1}$ and that she does not know whether her height should be in $I_{2}$ or $I_{3}$ :

(44) $\forall w^{\prime} \in \operatorname{Dox}_{M}(w)$,

$$
\text { [if } \left.I_{1}(w)=1, I_{1}\left(w^{\prime}\right)=1\right] \wedge\left[\text { if } \neg I_{1}(w)=1, \neg I_{1}\left(w^{\prime}\right)=1\right]
$$
and $\exists w^{\prime} \in \operatorname{Dox}_{M}(w)$,

$$
\left(I_{2}(w)=1 \wedge \neg I_{2}\left(w^{\prime}\right)=1\right) \vee\left(\neg I_{2}(w)=1 \wedge I_{2}\left(w^{\prime}\right)=1\right)
$$

and $\exists w^{\prime} \in \operatorname{Dox}_{M}(w)$,

$$
\left(I_{3}(w)=1 \wedge \neg I_{3}\left(w^{\prime}\right)=1\right) \vee\left(\neg I_{3}(w)=1 \wedge I_{3}\left(w^{\prime}\right)=1\right)
$$

However, the problem is that the meaning expressed by this tentative complete answer above is not coherent. Suppose first that Mary's height should be in $I_{1}$. The complete answer states that Mary does not know that her height should be in $\neg I_{3}$, i.e., in the complement of interval $I_{3}$. From this it follows that for any interval contained in $\neg I_{3}$, Mary does not know that her height should be in it. Interval $I_{1}$ is contained in interval $\neg I_{3}$. But now we have derived that the complete answer states a contradiction: this is because it states that Mary knows that her height should be in $I_{1}$ and that she does not know that her height should be in $\neg I_{3}$, which is a contradiction. If Mary's height had to be in the complement of interval $I_{1}$ the same problem would be recreated, but this time with interval $I_{2}$. We might illustrate the contradiction that arises with the following example:

(45) \# Mary knows whether her height should be between o \& 5 or between $5 \& 10$

but She does not know whether her height should be between o \& 3 or between $3 \& 10$

and She does not know whether her height should be between o \& 7 or between $7 \& 10$ 
Wh-islands in degree questions

Thus, assuming an interval reading of degree questions it is also the case that no maximally informative true answer can be found, in other words that the complete answer would express a contradiction. This result does not depend on the particular choice of intervals, except that the maximally informative true answer cannot pick out the whole scale of degrees, amounting to Mary knows whether she should have a height, as in this case the alternatives would not contain a bigger interval with respect to which a contradiction could arise. This case however would violate the condition that a maximally informative true answer should be contextually informative. Notice that the reasoning above also did not depend on intervals being convex: the same reasoning could have been run assuming that intervals are concave, i.e., simply sets of degrees. ${ }^{14}$ Also, as before, the same type of island violation is predicted with other members of the class of responsive verbs.

\subsection{The ambiguity of how many questions}

Recall from Section 2 the case of the ambiguity of how many questions such as (4), or an analogous case with the question embedding predicate know in (46):

(46) How many books do you know whether you should burn?

As was discussed above, this question can be uttered felicitously in a situation where the hearer is assumed to have a particular set of books in mind, and the speaker wonders about the cardinality of that set. It cannot, on the other hand, be understood as asking whether there is a particular number of books (any books) that the hearer knows whether he should burn. In other words, it can have the reading exemplified in (47a) but not that in (47b):

(47) a. For what $n$, there are $n$-many books $X$ such that you know whether you should burn $X$ ?

b. \#For what $n$, you know whether it should be the case that there be $n$-many books that you burn?

14 For this reason non-scalar questions such as (i) (cf. Beck \& Rullmann 1999) can be predicted as well:

(i) A: How many people can play this game?

B: 2, 4 and 6 people can play this game. 
The second reading is analogous to the degree question discussed in the previous section, therefore its unacceptability follows from the same reasoning. What we need to show still is why the first, wide scope reading is predicted to be acceptable on the present proposal.

As before, it will be useful to spell out the $\mathrm{H} / \mathrm{K}$ denotation of the reading described above in (47a) in slightly more detail, as shown below:

$\left\{\quad \exists X,|X|=d_{1}\right.$ such that you know whether you should burn $X$, $\exists Y,|Y|=d_{2}$ such that you know whether you should burn $Y$, $\exists Z,|Z|=d_{3}$ such that you know whether you should burn Z, ... etc, for all degrees in $D \quad$ \}

Crucially, unlike in the case of the degree reading considered in the previous two sections, the propositions in (48) are not all logically independent. In particular for any two degrees $d_{1}$ and $d_{2}$, if $d_{1}<d_{2}$, then a proposition of the form $\exists X,|X|=d_{2}$ such that you know whether you should burn $X$ will entail the proposition $\exists Z,|Z|=d_{1}$ such that you know whether you should burn $Z$. This is because of the homogeneity presupposition on the distributive operator (cf. (33)), burning $X$ will entail burning every element of $X$, and not burning $X$ will entail not burning any element of $X$. Therefore the proposition represented schematically in (49a) will entail the proposition represented in (49b).

(49) $\quad$ a. $\quad \exists X$ such that $|X|=d_{2}$ and $\forall w^{\prime} \in \operatorname{Dox}_{M}(w)$, (if $\operatorname{burn}_{D} X$ in $w$, $\operatorname{burn}_{D} X$ in $w^{\prime}$ ) $\wedge$ (if $\neg \operatorname{burn}_{D} X$ in $w, \neg \operatorname{burn}_{D} X$ in $w^{\prime}$ )

b. $\exists Y$ such that $Y \in X$ and $|Y|=d_{1}$ and $\forall w^{\prime} \in \operatorname{Dox}_{M}(w)$, (if $\operatorname{burn}_{D} Y$ in $w$, $\operatorname{burn}_{D} Y$ in $w^{\prime}$ ) $\wedge$ (if $\neg \operatorname{burn}_{D} Y$ in $w, \neg \operatorname{burn}_{D} Y$ in $w^{\prime}$ )

The maximally informative answer then will always pick out the maximal degree $d$ to which a set of books corresponds. Suppose this degree is $d_{2}$. The propositions not entailed by this proposition in the answer set will be those that are about degrees above $d_{2}$. For all $d^{\prime}, d^{\prime}>d_{2}$ in (48), the negation of a proposition about d' will be consistent with the assertion of the proposed most informative answer. Thus the complete answer does not lead to contradiction and we correctly predict that the question in (46) will have the reading where the existential quantifier takes wide scope. The degree reading on the other hand will be excluded as before. 
Wh-islands in degree questions

A similar reasoning could be run if we assumed an interval-semantics for degrees. In this case, for any two intervals $I_{1}$ and $I_{2}$, if $I_{1}$ is contained in $I_{2}$ then a proposition of the form $\exists X,|X| \in I_{1}$ such that you know whether you should burn $X$ will entail the proposition $\exists Y,|Y| \in I_{2}$ such that you know whether you should burn $Y$. But from this it follows that the maximally informative answer will always pick out the smallest interval that contains the cardinality of the set $X$ in question, namely a singleton set of degrees $I_{d}$. The propositions not entailed by this proposition will be those which do not contain $I_{d}$, and the negation of these propositions will be always consistent with the assertion of the most informative answer.

\subsection{Wh-islands with embedded constituent questions}

For most speakers of English extraction from tensed embedded constituent questions is unacceptable, even if the extracted element ranges over individuals. In many other languages the situation is similar (e.g., French, Dutch), although it has also been noted that some languages, e.g., Hungarian, do allow such extractions (cf. Szabolcsi \& Zwarts 1993).

(50) */?Which question do you know who answered correctly?

(51) *A quelle question sais tu qui a répondu correctement? To which problem know you who has answered correctly?

'Which question do you know who answered correctly' [French]

(52) ?Melyik kérdést tudod hogy ki válaszolta meg helyesen $t_{i}$ ? Which problem know.2sG that who solved PRT correctly

'Which question do you know who answered correctly' [Hungarian]

Given the cross-linguistic difference, and the fact that questions over individuals are also unacceptable, extraction from tensed interrogative complements is usually thought to create strong islands. For this reason they do not fall under the scope of this paper.

However, if the main verb in the embedded complement is not tensed it seems that questions over individuals are acceptable for many speakers even in English. But lack of tense does not improve corresponding degree questions, which are still odd. Therefore it is usually assumed that the contrast exemplified in (53) shows that (53b) is a genuine weak island and so it does fall under the scope of the present paper.

(53) a. ?Which problem does Mary know who should solve? 
b. *How tall does Mary know who should be?

In the remainder of this section I show that the unacceptability of examples such as (53b) can be reduced to the same reasoning that lead to the ungrammaticality of embedded whether questions.

\subsubsection{Embedded questions and exhaustivity}

A well-known issue concerning the nature of the meaning of constituent questions is that of exhaustivity. One of the main reasons why Karttunen's (1977) sets-of-propositions account of interrogatives was argued to be unsatisfactory by Groenendijk \& Stokhof $(1982,1984)$ (henceforth G\&S) was that it could not account for strong exhaustivity of wh-questions in embedded positions. The term strong exhaustivity refers to the kind of inference illustrated in (54), where the statement in (54a) in a situation (54b) leads to the inference (54C):

(54) a. John knows who left.

b. Mary and Sue left, Fred and Bill did not leave.

c. John knows that Mary and Sue left and that Fred and Bill did not leave.

It was argued by G\&S that this inference is intuitively valid, in other words for John to know who left means that he must be able to divide the domain of individuals under consideration into leavers and non-leavers, which in turn means that John must believe about the actual leavers that they left, and believe about the actual non-leavers that they did not leave. Karttunen's (1977) theory only accounts for the first half of this inference: it predicts that John is able to identify the set of actual leavers as leavers, but is compatible with the possibility that he has mistaken beliefs about the non-leavers, falsely believing of some of them that they have left. Thus Karttunen's theory only predicts a weaker inference, called weak exhaustivity, illustrated below:

(55) a. John knows who left.

b. Mary and Sue left (Fred and Bill did not leave).

c. John knows that Mary and Sue left.

Karttunen's and G\&S's theory does not differentiate between predicates with respect to whether their complements are understood exhaustively or 
not: They are all weakly (in the case of Karttunen) or strongly (as in G\&S) exhaustive. Heim (1994) and following her Beck \& Rullmann (1999), Sharvit (1997) and Guerzoni \& Sharvit (2004) have argued for a theory that has more flexibility, namely allows some embedded questions to be understood as weakly exhaustive. Nevertheless it is fair to say that the properties of weakly exhaustive question embedding predicates are not yet well understood (cf. also Klinedinst \& Rothschild 2011 for a recent discussion).

In the next section I show how the analysis presented in the previous section carries over to the cases of wh-islands with embedded constituent questions. The cases discussed will be mainly question embedding verbs that require a strongly exhaustive reading of their interrogative complement. Extraction from weakly exhaustive question embedding verbs will be addressed briefly at the end of the section.

\subsubsection{Extraction from embedded constituent questions}

Strong exhaustivity can be paraphrased in terms of embedded yes/no questions: E.g., (54a) under the strong exhaustive interpretation says that for every individual in the relevant domain, John knows whether they have left. This is the property that the present analysis exploits in order to explain the oddness of examples such as (53b), repeated below:

(56) *How tall does Mary know who should be?

In the case of embedded constituent question complements of verbs such as know that require a strongly exhaustive interpretation, the same problem that we have observed in the previous section reappears, but multiple times. For concreteness, I illustrate the problem using the classical semantics for degrees, but it should be borne in mind that the same results would be derived by using the interval semantics as well. First, observe the Hamblindenotation of (56) below:

(57) $\lambda q . \exists d\left[d \in D_{d} \wedge q=\lambda w\right.$. $\operatorname{knows}(w)$ (Mary, $\lambda p . \exists x[$

$$
\left.p=\lambda w^{\prime} . x \text { 's height should be (at least) } d \text { in } w^{\prime}\right] \text { )] }
$$

Imagine that there are 3 individuals in the domain $A, B$ and $C$, and 3 degrees. Then the informal representation of the denotation of the question above is as follows: 
(58) $\left\{\right.$ that Mary knows (for which $x \in\{A, B, C\}, x$ 's height should be $d_{1}$ ), that Mary knows (for which $x \in\{A, B, C\}, x$ 's height should be $d_{2}$ ), that Mary knows (for which $x \in\{A, B, C\}, x$ 's height should be $d_{3}$ ) $\}$

Recall that the strongly exhaustive meaning for the question embedding predicate know places a constraint on the true as well as the false alternatives. Given this, our question denotation equals the following set of propositions:

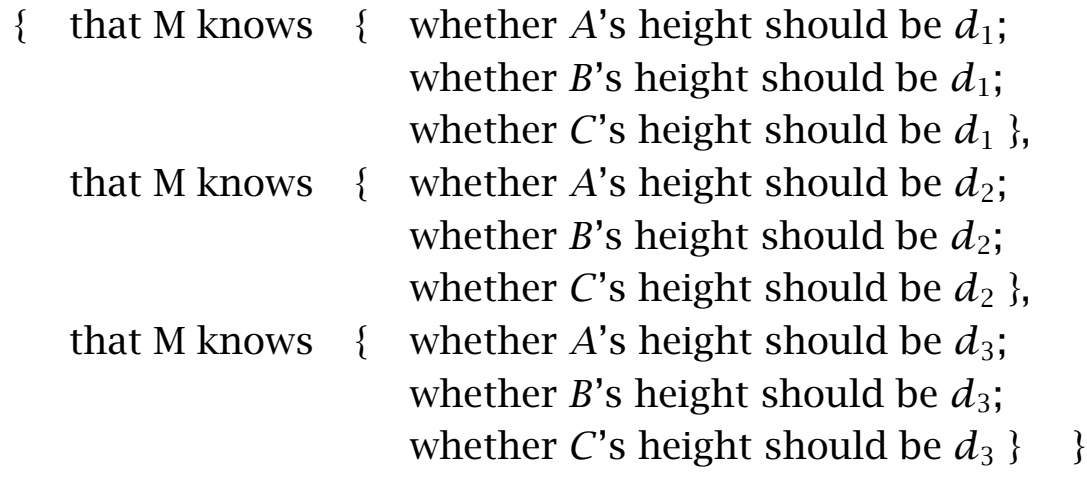

Before we proceed, a note about negation is necessary: It has been sometimes observed (e.g., D. Fox, class notes) that the negation of a strongly exhaustive predicate is stronger than expected: e.g., John does not know who came seems to suggest that for no individual does John know whether they came. This is surprising because by simple negation we would only expect a much weaker meaning, according to which John does not know for everyone whether they came. In other words, the question below in (6oa) seems to have the stronger meaning shown in (6ob) instead of the predicted weaker (6oc):

(60) a. John does not know who came.

b. $\forall p \in Q_{H}(w)$, John does not know whether $p$.

c. $\neg \forall p \in Q_{H}(w)$, John knows whether $p$.

In the discussion that follows I will take this fact at face value, without providing an explanation. ${ }^{15}$ Given this, the complete answer conjoins the most informative true answer with the strengthened negation of the false alternatives. Now, a complete answer Mary knows who should be $d_{1}$-tall will state:

15 A possible idea, raised both by anonymous reviewers and D. Fox (class notes) is that this effect has to do with a homogeneity assumption associated with the denotation of the embedded question. Exploring the exact workings of this idea in detail would however would take me too far afield. 
Wh-islands in degree questions

(61) that M knows whether $A$ 's height should be $d_{1}$

\& that M knows whether $B$ 's height should be $d_{1}$ $\&$ that $M$ knows whether $C$ 's height should be $d_{1}$

\& that $\mathbf{M} \neg$ know whether $A$ 's height should be $d_{2}$

\& that M $\neg$ know whether $B$ 's height should be $d_{2}$ \& that $M \neg$ know whether $C$ 's height should be $d_{2}$

\& that $\mathbf{M} \neg$ know whether $A$ 's height should be $d_{3}$

\& that M $\neg$ know whether $B$ 's height should be $d_{3}$ \& that $M \neg$ know whether $C$ 's height should be $d_{3}$

Looking more closely at the conjunction of propositions above, we can observe that exactly the same problem that arose with the embedded whether questions is recreated, but many times! Example (62) is an alternative representation of (61): observe that each boxed part below corresponds to an embedded contradictory whether question:

(62)

\begin{tabular}{|c|c|c|c|c|}
\hline that $\mathrm{M}$ knows if $\mathrm{A}\left(d_{1}\right)$ & \& & that M knows if $\mathrm{B}\left(d_{1}\right)$ & $\&$ & that M knows if $\mathrm{C}\left(d_{1}\right)$ \\
\hline \& that $\mathrm{M} \neg$ know if $\mathrm{A}\left(d_{2}\right)$ & \& & that $\mathrm{M} \neg$ know if $\mathrm{B}\left(d_{2}\right)$ & $\&$ & that $\mathrm{M} \neg$ know if $\mathrm{C}\left(d_{2}\right)$ \\
\hline$\&$ that $\mathrm{M} \neg$ know if $\mathrm{A}\left(d_{3}\right)$ & $\&$ & that $\mathrm{M} \neg$ know if $\mathrm{B}\left(d_{3}\right)$ & $\&$ & that $\mathrm{M} \neg$ know if $\mathrm{C}\left(d_{3}\right)$ \\
\hline
\end{tabular}

Thus the problem of embedded constituent questions simply reduces to the problem of embedded whether questions, which have been argued to lead to a contradiction in the previous section.

\subsubsection{Weakly exhaustive predicates}

As was noted above, there are question-embedding predicates that do not require their complement to receive a strongly exhaustive reading, such as regret, predict, etc. (cf. Heim 1994 and also Beck \& Rullmann 1999, Sharvit 1997). Nevertheless, extraction from the complement of such predicates also results in unacceptability, as shown by the example below:

(63) *How fast did Mary predict who should be?

As it turns out, even some weakly exhaustive question embedding verbs are predicted to lead to ungrammaticality in wh-island constructions. Imagine, as before, that there are 3 individuals in the domain $A, B$ and $C$, and 3 degrees $d_{3}>d_{1}>d_{2}$. Given that these question-embedding predicates are weakly 
exhaustive, predicting who will drive $100 \mathrm{mph}$ will be true if all the people who should drive loomph were predicted to do so. Represented schematically, for (63) the following denotation is predicted:

(64) \{ that Mary predicted who should be $d_{1}$-fast, that Mary predicted who should be $d_{2}$-fast, that Mary predicted who should be $d_{3}$-fast $\left.\quad\right\}$

Notice that the alternatives in (64) do not entail each other. Spelling out (64) a little bit more, and assuming only singular answers (i.e., excluding for the moment alternatives such as that Mary predicted that $A+C$ should be $d_{1}$-fast) the above can be described as follows:

(65) \{if A should be $d_{1}$-fast, then Mary predicted that A should be $d_{1}$-fast $\vee$ if B should be $d_{1}$-fast then Mary predicted that B should be $d_{1}$-fast $\checkmark$ if $C$ should be $d_{1}$-fast then Mary predicted that C should be $d_{1}$-fast if A should be $d_{2}$-fast, then Mary predicted that A should be $d_{2}$-fast $\vee$ if B should be $d_{2}$-fast then Mary predicted that B should be $d_{2}$-fast $\checkmark$ if $C$ should be $d_{2}$-fast then Mary predicted that C should be $d_{2}$-fast if A should be $d_{3}$-fast, then Mary predicted that A should be $d_{3}$-fast $\vee$ if B should be $d_{3}$-fast then Mary predicted that B should be $d_{3}$-fast $\checkmark$ if $\mathrm{C}$ should be $d_{3}$-fast then Mary predicted that C should be $d_{3}$-fast \}

If we were to select that Mary predicted who should be $d_{1}$-fast as the most informative answer, this would entail that we need to negate the remaining alternatives in the question denotation. This is illustrated below.

(66) \{ if A should be $d_{1}$-fast, then Mary predicted that A should be $d_{1}$-fast $V$ if B should be $d_{1}$-fast then Mary predicted that B should be $d_{1}$-fast $\checkmark$ if $C$ should be $d_{1}$-fast then Mary predicted that C should be $d_{1}$-fast and

$\neg$ if A should be $d_{2}$-fast, then Mary predicted that A should be $d_{2}$-fast $\wedge$ $\neg$ if B should be $d_{2}$-fast then Mary predicted that B should be $d_{2}$-fast $\wedge \neg$ if $C$ should be $d_{2}$-fast then Mary predicted that C should be $d_{2}$-fast and

$\neg$ if A should be $d_{3}$-fast, then Mary predicted that A should be $d_{3}$-fast $\wedge$ $\neg$ if B should be $d_{3}$-fast then Mary predicted that B should be $d_{3}$-fast $\wedge \neg$ if $C$ should be $d_{3}$-fast then Mary predicted that C should be $d_{3}$-fast \} 
Now suppose that the truth of the first conjunct is based on Mary making a correct prediction about $B$ (indicated in boldface). In this context the above complete answer asserts both that she predicted that $B$ should be $d_{1}$-fast and that she did not predict that $B$ should be $d_{2}$-fast or $d_{3}$-fast. But this leads to a contradiction because for any $d_{1}>d_{2}$, it follows from the proposition that Mary predicted that $B$ should be $d_{1}$-fast that she predicted that $B$ should be $d_{2}$-fast. Naturally, the same reasoning can be extended to answers based on the properties of any other individual in the domain, in this case $A$ and $C$. It can be shown that we would obtain the same result if plural answers were allowed, as long as the predicate is understood distributively, as was discussed in Section 3.1. In essence, it is still the two properties discussed in connection with know above that lead to trouble here: that the question embedding construction ' $x V-d Q$ ' is equivalent to a disjunction of declarative propositions that are themselves monotonic. As the denotation of the $w h$-island construction will contain many such alternative disjunctions, with the disjuncts not being independent from each other, no maximally informative answer will be found. Given all this, the above complete answer could only be contradiction-free if $d_{1}$ was the minimal degree on the scale. Such cases however are ruled out by the context-sensitive version of the MIP given in (19). This predicts the above question to be unacceptable as well. Question verbs such as agree or decide are expected to work similarly as well.

In some other cases of weakly exhaustive predicates, e.g., regret, the alternative (non-interrogative) propositions are not monotonic: that John regrets that $A$ is $n$-tall does not entail anything with respect to any other degree. This suggests that we should not find weak-islands with this predicate, contrary to fact. However, in this case a different kind of problem arises: here even the potential answers are independently ill-formed:

*How fast does Mary regret who should be?

$\left\{\right.$ \# that Mary regrets who should be $d_{1}$-fast, \# that Mary regrets who should be $d_{2}$-fast, \# that Mary regrets who should be $d_{3}$-fast \}

As the alternative potential answers in (68) are ill-formed to begin with, in this case the island violation arises as no well-formed maximally informative answer can be found. Why the alternatives in (68) are not well-formed is an interesting question in its own right, but one that goes beyond the scope of this paper. 
Márta Abrusán

\section{Obviation phenomena}

As was mentioned at the outset, it is possible to obviate $w h$-islands in some cases. For example, verbs belonging to the class of inquisitive predicates produce a much weaker effect, if any. Second, an extra universal modal or attitude verb can ameliorate island effects as well. Finally, contextually specified choices (multiple choice test scenarios) can improve cases of island violations as well, as was observed in Kroch 1989. This section discusses these effects and shows that they are predicted by the present account.

\subsection{Fox's (2007) generalization and modal obviation}

Fox (2007) proposed the following generalization about exhaustification failure:

(69) Fox's (2007) generalization

Let $p$ be a proposition and $A$ a set of propositions.

$p$ is non-exhaustifiable given $A$ : $[\mathrm{NE}(p)(A)]$ if the denial of all alternatives in $A$ that are not entailed by $p$ is inconsistent with $p$.

$[\operatorname{NE}(p)(A)] \Leftrightarrow p \wedge \bigcap\{\neg q: q \in A \wedge \neg(p \Rightarrow q)\}=\emptyset$

Suppose that $\mathrm{p}$ corresponds to a set of worlds $W_{p}$. If a proposition $p^{\prime}$ is not entailed by $p$, then there is some world in $W_{p}$ that makes $p^{\prime}$ false. Thus, for each $q$ in $A$ not entailed by $p$, there is some world $w^{\prime}$ in $W_{p}$ such that $q\left(w^{\prime}\right)=0$. The question is whether there is a world in $W_{p}$ in which all the alternatives $q$ in $A$ that are not entailed by $p$ are false, in other words whether $\bigcap\{\neg q: q \in A \wedge \neg(p \Rightarrow q)\}$ has a non-empty intersection with $p$. A trivial way this might happen is if either p or $\bigcap\{\neg q: q \in A \wedge \neg(p \Rightarrow q)\}$ itself is empty. A more interesting case is if neither $p$ nor $\bigcap\{\neg q: q \in A \wedge \neg(p \Rightarrow q)\}$ are empty, only their intersection is. Fox (2007) proves that obviation by universal, but not by existential quantification is a logical property of such sets:

(70) A universal modal eliminates non-exhaustifiability:

If $p$ is consistent, $\operatorname{NE}(\square p,(\square A))$ does not hold (even if $\operatorname{NE}(p, A)$ holds)

$$
\text { (where } \square A=\{\square p: p \in A)\} \text { ) }
$$

To say that $\operatorname{NE}(\square p,(\square A))$ does not hold means that $(\square p,(\square A))$ is exhaustifiable at least given some modal base. ${ }^{16}$ So we need to prove that there is some

16 I.e., what is proven here is that it is not the case that for all modal bases, $\operatorname{NE}(\square p(\square A))$ holds. This means that when the grammaticality of a given example is calculated, it is not 
modal base given which ( $\square p,(\square A))$ is exhaustifiable. Let the modal base for $\square$ in $w^{0}$ be the set of worlds $W_{p}$ in which $p$ is true: $\{w: p(w)=1\}$. For every $q \in A$ that is not entailed by $p$, there is some world $w^{\prime}$ in the modal base $W_{p}$ that falsifies $q$. Therefore, given this modal base, for each $q \in A, \diamond \neg q$ is true. Since $\diamond \neg q$ is equivalent to $\neg \square q$, the denial of each of the propositions $\square q$ in $\square A$ will not be inconsistent with $\square p$, even if $\operatorname{NE}(p, A)$ holds.

(71) An existential modal does not eliminate non-exhaustifiability: if $\mathrm{NE}(p, A)$ holds, so does $\mathrm{NE}(\diamond p, \diamond A) \quad($ where $\diamond A=\{\diamond p: p \in A)\})$

Suppose that the intersection of $p$ and $\bigcap\{\neg q: q \in A\}$ is empty, but the intersection of $\diamond p$ and $\bigcap\{\neg \diamond q: q \in A\}$ is not. Under the assumption that all the alternatives are interpreted relative to the same modal base, this means that there must be some modal base that makes $\diamond p$ true, but makes every proposition in $\diamond A$ not entailed by $\diamond p$ false. This means that in the modal base, there is some world in which $p$ is true, but there is no world in which any $q$ in $A$ (not entailed by $p$ ) is true. Let's take a world in the modal base in which $p$ is true, $w_{p}$. Given the above, for any $q$ in $A$ that is not entailed by $p, q\left(w_{p}\right)=0$. But this means, that there is a world that makes $p$ true but makes all its independent alternatives false, namely $w_{p}$. In other words, $p$ is exhaustifiable given $A$ after all, contrary to our initial assumptions, which shows that our initial assumption leads to a contradiction.

Observe now that it was a property of the set of propositions corresponding to the $\mathrm{H} / \mathrm{K}$ denotation of questions such as (41) that each alternative $p^{\prime}$ to $p$ in the $\mathrm{H} / \mathrm{K}$ denotation not entailed by $p$ there are contexts in which $p^{\prime}$ could be denied consistently with $p$, but there was no context in which all the alternatives to $p$ (not entailed by $p$ ) could be denied consistently with asserting $p$. The situation that we observe then in connection with $w h$-islands falls under the generalization of Fox (2007). This however makes the prediction that we should be able to observe modal obviation effects in the case of $w h$-islands as well. The next sections will show that this is indeed the case.

necessarily the same modal base that is taken into account when checking its grammaticality, what is checked is whether it has the logical property of being (non-)exhaustifiable in the above sense. Thanks to an anonymous reviewer for pointing out this issue. 
Márta Abrusán

\subsection{Wonder-type predicates}

As it was mentioned in the beginning of Section 3, degree questions with inquisitive predicates such as wonder, consider, investigate, examine, etc. are markedly better than similar questions with responsive predicates. Some of the relevant examples are repeated below: ${ }^{17}$

(72) a. ?How many inches of legroom are the airline executives considering whether we can remove from economy class cabins (without people noticing)?

b. ?How much wine are scientists investigating/examining whether it is useful to drink in order to stay healthy?

c. ?How many kilograms are the boxers wondering whether it is worth losing next year (in order to have a better chance to win)?

This fact has a principled explanation under the present proposal. Inquisitive predicates have a complex lexical semantics: they contain both a buletic and a doxastic component. According to Guerzoni \& Sharvit (2004) e.g., the lexical semantics of wonder is essentially paraphrasable as 'want to know' and can be represented as follows:

(73) wonder $(w)\left(x, Q_{H}(w)\right)$ is defined iff $\neg \forall p \in Q_{H}(w), x$ believes $p$

if defined, wonder $(w)\left(x, Q_{H}(w)\right)$ is true iff

$\forall p \in Q_{H}(w), x$ wants-to-know whether $p$ in $w$.

This means that in the lexical representation of wonder there is a universal quantifier over worlds above the doxastic attitude. Therefore this case falls under Fox's (2007) generalization, i.e., the universal quantifier is expected to obviate the exhaustification failure. ${ }^{18}$

17 Notice that Kroch's (1989) example in (10) contains argue about, which belongs to this group of predicates as well. Further, it seems, as noted by an anonymous reviewer, that the progressive might contribute to the relative acceptability of the sentences above and similar examples are harder to find without the progressive. What role the progressive might play is an interesting question that I leave for further investigation. Notice however that island variations that contain responsive predicates do not improve from the progressive.

18 An anonymous reviewer notes that it is also the case that the property that was mentioned in connection with know, namely that ' $x$ knows whether $p$ ' is equivalent to ' $x$ knows that $p$ or $x$ knows that not $p$ ' does not hold for wonder (or for want to know), so that might be enough reason to suppose that the examples with wonder not ruled out. In a sense, these are two sides of the same coin, since it is also because of the extra universal attitude that ' $x$ wants to know whether $p$ ' is not equivalent to ' $x$ wants to know that $p$ or $x$ wants to know that not $p$.' Either way, what is assumed here that it is the extra lexical modal component, that helps to obviate the island violation. 
Wh-islands in degree questions

Let's spell out what it means if $x$ wants to know whether $p$. Using a Hintikka-style semantics for attitude verbs such a meaning could be expressed as follows:

(74) ' $x$ wants-to-know whether $p$ in $w$ ' is true in w iff

for $\forall w^{\prime} \in \operatorname{Bul}_{x}(w)$,

if $p(w)=1, x$ knows $p$ in $w^{\prime}$, and

if $p(w)=0, x$ knows $\neg p$ in $w^{\prime}$

where $\operatorname{Bul}_{x}(w)=\left\{w^{\prime} \in W: x\right.$ 's desires in $w$ are satisfied in $\left.w^{\prime}\right\}$

'in every world in which $x$ 's desires are satisfied, if $p, x$ knows that $p$ and if not $p, x$ knows that not $p$,

Given the above, the meaning of a question where a degree phrase moves out from the complement of wonder will be as follows:

(75) a. ?How many pounds are the boxers wondering whether to lose next year?

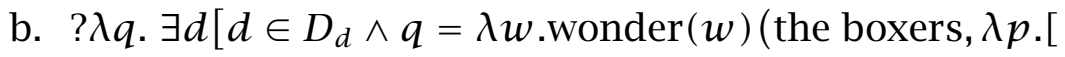

$$
\begin{aligned}
& p=\lambda w^{\prime} . \text { lose at least } d \text { pounds in } w^{\prime} \vee \\
& \left.\left.\left.p=\lambda w^{\prime} . \neg \text { lose at least } d \text { pounds in } w^{\prime}\right]\right)\right]
\end{aligned}
$$

Informally, we might represent the set described above as follows:

(76) \{ that the boxers are wondering whether to lose at least $d_{1}$ pounds, that the boxers are wondering whether to lose at least $d_{2}$ pounds, that the boxers are wondering whether to lose at least $d_{3}$ pounds, etc, for all intervals in $\left.D_{d}\right\}$

Somewhat more precisely the above can be represented as below:

(77) $\left\{\forall w^{\prime} \in \operatorname{Bul}_{M}(w)\right.$, if $d_{1 w}, b^{\prime} s$ know $d_{1}$ in $w^{\prime} \wedge$

$$
\text { if } \neg d_{1 w}, b^{\prime} s \text { know } \neg d_{1} \text { in } w^{\prime} \text {, }
$$

$\left\{\forall w^{\prime} \in \operatorname{Bul}_{M}(w)\right.$, if $d_{2 w}, b^{\prime} s$ know $d_{2}$ in $w^{\prime} \wedge$ if $\neg d_{2 w}, b^{\prime} s$ know $\neg d_{2}$ in $w^{\prime}$,

$\left\{\forall w^{\prime} \in \operatorname{Bul}_{M}(w)\right.$, if $d_{3 w}, b^{\prime} s$ know $d_{3}$ in $w^{\prime} \wedge$

if $\neg d_{3 w}, b^{\prime} s$ know $\neg d_{3}$ in $w^{\prime}$, etc. for all intervals in $D_{d} \quad$ \}

where $d_{n w}$ is a notational shorthand for the boxers should lose at least $d_{n}$ pounds in $w$. 
In effect we have the same representation as before with know-class predicates, but with a universal modal above them, the segment of the meaning of wonder that can be paraphrased with the attitude predicate want. Given Fox's generalization, this means that the example in (75) should not lead to exhaustification failure.

We can illustrate this informally as follows. The alternative answers in (77) above do not entail each other. Suppose first that the answer to the question is based on the boxers' wondering about some degree $d_{2}$ whether they have to lose that many pounds. It does not follow, for any $d^{\prime}$ such that $d_{2} \neq d^{\prime}$, that this proposition entails the proposition that the boxers are wondering about some degree d' whether they have to lose $d^{\prime}$-many pounds. Thus e.g., the answer that the boxers are wondering whether they have to lose 3 pounds does not entail, for any degree other than 3 , that the boxers are wondering whether they have to lose that many pounds. Since the alternative answers in (77) do not entail each other in any context, there is no obstacle to finding a most informative true answer. The same would be true were it the case the true answer was based on Mary's wondering about a certain degree whether she should not be that fast.

However, the only context in which there will be a maximally informative true answer is where there is a single contextually salient degree, such that the boxers are wondering whether they have to lose THAT much. Alternatively, using the interval semantics of degrees, there could be an interval such that the boxers are wondering whether the amount of pounds they have to lose should be in THAT interval, e.g., between 2 and 5 pounds. These are fairly unnatural contexts, and therefore the question sounds pragmatically odd. Once we enhance the plausibility of such contexts, the questions become as acceptable as their counterparts with wh-words ranging over individuals.

Let's point out a crucial difference between islands that arise with knowclass predicates and those that arise with wonder-class predicates: The presupposition of the former can never be met and such examples are therefore excluded by grammar, and context can do little to ameliorate them. The presupposition of the latter can be met, but only in pragmatically very implausible contexts, and such examples are therefore felt to be odd out of the blue, but can be improved with the right kind of context. This effect is similar to that observed by Abrusán \& Spector (2011) in connection with quasi-negative islands such as How many children does none of these women have?, that are unacceptable out of the blue, however become acceptable once a certain specific context in which they do have a maximally informative true answer is made salient. 
Wh-islands in degree questions

\subsection{Modal obviation}

Fox's generalization makes the prediction that we should be able to observe modal obviation effects in $w h$-islands with overt universal quantifiers as well. As was pointed out in the introduction of this paper, it seems that this is indeed the case, although the required examples and the situations that make them good are rather complex, and therefore pragmatically odd out of the blue. Consider the following case.

(78) Context: Cough syrup contains some steroids. For this reason, olympic athletes need to inform the World Anti-Doping Agency (WADA) if they have to take more than a certain amount of it. But I forgot what this amount was, so I ask my friend, Michael Phelps:

?How much cough syrup does the WADA need to know whether you took?

(79) Context: Losing a lot of weight too fast can also be suspicious when it comes to olympic athletes. Therefore WADA has an interest in such cases as well.

?How many pounds does the WADA want to know whether the boxers lost?

It seems that the examples above could indeed be uttered felicitously, and that there is a grammaticality contrast between these examples and "How much cough syrup does the WADA know whether you took? and "How many pounds does the WADA want to know whether the boxers lost? Indeed the complete answer to (79) does not have to be contradictory. E.g., suppose $d_{1}$ is some degree such that the WADA needs to know whether the boxers lost that many pounds. Then one can truthfully utter:

(80) WADA wants to know whether the boxers lost $d_{1}$-many pounds \& for every $d_{2} \in D, d_{1} \neq d_{2}$, the WADA does not want to know whether the boxers lost $d_{2}$-many pounds.

Further, for many speakers ${ }^{19}$ an existential modal in the same position does not seem to achieve the same effect, even if we modify the context to make this answer more plausible. Suppose now that there is a regulation that the

19 However, some of my informants do find acceptable if a suitable context is presented. At present I do not understand why this is so. 
public cannot know about degrees of weight loss of the boxers, except for a certain degree. So I ask:

???How many pounds is the public allowed to know whether the boxers lost?

The modal obviation facts thus argue that the account based on maximization failure is on the right track.

\subsection{Multiple choice questions}

Other examples where $w h$-islands are felt to be improving are cases of multiple choice tests, where a limited range of answers is offered. For example:

(82) ?How many pounds do the boxers know whether they need to lose next year: 5 pounds or 7 pounds?

In these cases too, we see an improvement that depends on the context of the question. However, unlike in the case of quasi-islands that arise with predicates such as wonder and certain negative islands discussed in Abrusán \& Spector 2011, here the improvement comes from severely restricting the domain of alternatives in such a way that the issues that lead to ungrammaticality before do not even arise, and thus no contradiction is predicted. In other words, by carefully providing only such alternative answers from which it is possible to form complete answers that are not contradictory, ungrammaticality can be avoided. ${ }^{20}$

\section{Conclusion}

This paper has argued that Fox \& Hackl's (2007) idea according to which the unacceptability of negative degree islands results from the maximal informativity requirement can be extended to cover $w h$-islands that arise with degree questions. It was shown that wh-islands with know-class predicates cannot receive a maximally informative true answer, and are thus unacceptable. Wh-islands with wonder-type predicates are predicted to have a most informative true answer only in very special and unnatural contexts, which

20 Notice that the above example does not violate the informativity clause in MIP, because it is still the case that any of the alternatives could be the true answer. 
Wh-islands in degree questions

renders them pragmatically odd. A similar situation is shown to arise with certain cases of modal obviation in Section 4.3. The paper presents two ways in which the unacceptability of $w h$-islands can be derived: using the classical and the interval based degree semantics. Thus this paper suggested that Kroch's (1989) informal account of wh-islands was on the right track, and gave an explanation for why in certain cases most informative answers are impossible or contextually restricted.

\section{Acknowledgements}

This paper has distant roots in my MIT Ph.D. dissertation: Special thanks to my thesis advisor Danny Fox, and my thesis committee: Gennaro Chierchia, Irene Heim, David Pesetsky. Thanks also to the three anonymous reviewers and the editors-in-chief for their extremely helpful comments, and to Danny Fox for pointing out a serious mistake in a previous version of this manuscript. I would like to thank also Klaus Abels, Sigrid Beck, Emmanuel Chemla, Paul Egré, Danny Fox, Winnie Lechner, Øystein Nilsen, Philippe Schlenker and the audience at the EGG Summerschool in Debrecen and Sinn und Bedeutung 13, Stuttgart for comments, questions and suggestions. I acknowledge financial support (in part) by the European Science Foundation (Euryi project "Presupposition: a formal pragmatic approach"), the Hungarian National Science Fund NF-73537 and the Mellon Foundation. All remaining errors are my own.

\section{References}

Abrusán, Márta. 2011. Presuppositional and negative islands: A semantic account. Natural Language Semantics 19(3). 257-321. http://dx.doi.org/10.1007/s11050-010-9064-4.

Abrusán, Márta. in preparation. Weak island semantics. Oxford: Oxford University Press.

Abrusán, Márta \& Benjamin Spector. 2011. An interval-based semantics for degree questions: negative islands and their obviation. Journal of Semantics 28(1). 107-147. http://dx.doi.org/10.1093/jos/ffqo13.

Beck, Sigrid. 1996. Wh-constructions and transparent logical form. Tübingen: University of Tübingen dissertation.

Beck, Sigrid. 2001. Reciprocals are definites. Natural Language Semantics 9(1). 69-138. http://dx.doi.org/10.1023/A:1012203407127. 
Beck, Sigrid \& Hotze Rullmann. 1999. A flexible approach to exhaustivity in questions. Natural Language Semantics 7(3). 249-298. http://dx.doi.org/10.1023/A:1008373224343.

Chomsky, Noam. 1986. Barriers. Cambridge, Mass: The MIT Press.

Cinque, Guglielmo. 1990. Types of A-dependencies. Cambridge, Mass: The MIT Press.

Comorovski, Ileana. 1989. Discourse linking and the wh-island constraint. In Proceedings of the 19th meeting of the North East Linguistic Society, 78-96. Amherst, Mass.: GLSA.

Cresti, Diana. 1995. Extraction and reconstruction. Natural Language Semantics 3(1). 79-122. http://dx.doi.org/10.1007/BFo1252885.

Dayal, Veneeta. 1996. Locality in wh-quantification. Boston: Kluwer Academic Publishers.

Fox, Danny. 1995. Economy and scope. Natural Language Semantics 3(3). 283-341. http://dx.doi.org/10.1007/BFo1248820.

Fox, Danny. 2007. Too many alternatives: Density, symmetry and other predicaments. In Proceedings of SALT 17, 89-111. Ithaca, N.Y.: CLC Publications. http://dx.doi.org/1813/11295.

Fox, Danny \& Martin Hackl. 2007. The universal density of measurement. Lingustics and Philosophy 29(5). 537-586. http://dx.doi.org/10.1007/s10988oo6-9004-4.

Gajewski, Jon. 2002. On analyticity in natural language. Manuscript. http: //gajewski.uconn.edu/papers/analytic.pdf.

Gajewski, Jon. 2005. Neg-raising: Polarity and presupposition: Massachusetts Institute of Technology dissertation. http://dx.doi.org/1721.1/33696.

Ginzburg, Jonathan. 1995. Resolving questions II. Linguistics and Philosophy 18(6). 567-6o9. http://dx.doi.org/10.1007/BFoog83299.

Groenendijk, Jeroen \& Martin Stokhof. 1982. Semantic analysis of wh-complements. Linguistics and Philosophy 5(2). 175-233. http://dx.doi.org/10.1007/BFoo351052.

Groenendijk, Jeroen \& Martin Stokhof. 1984. Studies on the semantics of questions and the pragmatics of answers. Amsterdam: Universiteit van Amsterdam dissertation.

Guerzoni, Elena \& Yael Sharvit. 2004. A question of strength: On NPIs in interrogative clauses. Linguistics and Philosophy 30(3). 361-391. http://dx.doi.org/10.1007/s10988-007-9014-x.

Hamblin, Charles L. 1973. Questions in Montague English. Foundations of Language 10(1). 41-53. http://www.jstor.org/stable/25000703. 
Wh-islands in degree questions

Heim, Irene. 1994. Interrogative semantics and Karttunen's semantics for know. In Rhonna Buchalla \& Anita Mittwoch (eds.), IATL, 128-144. Akademon, Jerusalem. http://semanticsarchive.net/Archive/jUzYjkıO.

Heim, Irene. 2006. Remarks on comparative clauses as generalized quantifiers. Manuscript. http://semanticsarchive.net/Archive/mJiMDBIN.

Heycock, Caroline. 1995. Asymmetries in reconstruction. Linguistic Inquiry 26(4). 547-570. http://www.jstor.org/stable/4178914.

Karttunen, Lauri. 1977. Syntax and semantics of questions. Linguistics and Philosophy 1(1). 3-44. http://dx.doi.org/10.1007/BFo0351935.

Klinedinst, Nathan \& Daniel Rothschild. 2011. Exhaustivity in questions with non-factives. Semantics and Pragmatics 4(2). 1-23. http://dx.doi.org/10.3765/sp.4.2.

Kroch, Antony. 1989. Amount quantification, referentiality, and long whmovement. Manuscript. http://citeseerx.ist.psu.edu/viewdoc/download? doi=10.1.1.53.8124\&rep=rep1\&type=pdf.

Lahiri, Utpal. 2002. Questions and answers in embedded contexts. Oxford: Oxford University Press.

Link, Gödehard. 1983. The logical analysis of plurals and mass terms: A lattice-theoretical approach. In Robert Bauerle, Christoph Schwarze \& Arnim von Stechow (eds.), Meaning, use, and interpretation of language, 302-323. Berlin: Walter de Gruyter.

Löbner, Sebastian. 1985. Definites. Journal of Semantics 4(4). 279-326. http://dx.doi.org/10.1093/jos/4.4.279.

Manzini, Rita. 1992. Locality. Cambridge, Mass: The MIT Press.

Pesetsky, David. 1987. Wh-in-situ: Movement and unselective binding. In Eric Reuland \& Alice ter Meulen (eds.), The representation of (in)definiteness, 98-129. Cambridge, Mass.: The MIT Press.

Rizzi, Luigi. 1990. Relativized minimality. Cambridge, Mass.: The MIT Press.

Rullmann, Hotze. 1995. Maximality in the semantics of wh-constructions. Amherst, Mass.: University of Massachusetts at Amherst dissertation.

Schwarzschild, Roger. 1996. Pluralities. Dordrecht: Kluwer Academic Publishers.

Schwarzschild, Roger. 2004. Scope-splitting in the comparative. Handout from MIT colloquium. http://www.rci.rutgers.edu/ tapuz/MITo4.pdf.

Schwarzschild, Roger \& Karina Wilkinson. 2002. Quantifiers in comparatives: A semantics of degree based on intervals. Natural Language Semantics 10(1). 1-41. http://dx.doi.org/10.1023/A:1015545424775.

Sharvit, Yael. 1997. The syntax and semantics of indirect binding. New 
Brunswick, New Jersey: Rutgers University dissertation.

Sharvit, Yael. 2002. Embedded questions and de dicto readings. Natural Language Semantics 10(2). 97-123. http://dx.doi.org/10.1023/A:1016573907314.

Starke, Michal. 2001. Move dissolves into merge: a theory of locality. Geneva: University of Geneva dissertation. http://ling.auf.net/lingBuzz/ooooo2. von Stechow, Arnim. 1984. Comparing semantic theories of comparison. Journal of Semantics 3(1-2). 1-77. http://dx.doi.org/10.1093/jos/3.1-2.1.

Szabolcsi, Anna \& Frans Zwarts. 1990. Semantic properties of composed functions and the distribution of wh-phrases. In Martin Stokhof \& Leen Torenvliet (eds.), Proceedings of the Seventh Amsterdam Colloquium, Amsterdam: Institute for Language, Logic and Information. http://keur. eldoc.ub.rug.nl/FILES/wetenschappers/8/110/110.pdf.

Szabolcsi, Anna \& Frans Zwarts. 1993. Weak islands and an algebraic semantics for scope taking. Natural Language Semantics 1(3). http://dx.doi.org/10.1007/BFoo263545. Reprinted, with minor modifications, in Anna Szabolcsi, ed., Ways of scope taking, 1997, Dordrecht: Kluwer Academic Publishers.

Márta Abrusán

University of Oxford

Somerville College,

OX2 6HD, UK

Phone : +44 1865270607

abrusan@alum.mit.edu 